\title{
How to interpret consolidation and creep in Yoldia clay
}

\author{
Elena Peri ${ }^{1, *}$, Lars Bo Ibsen $^{1}$, and Benjaminn Nordahl Nielsen ${ }^{1}$ \\ ${ }^{1}$ Department of Civil Engineering, Aalborg University, Denmark
}

\begin{abstract}
The aim of this paper is to define a guideline for an objective interpretation of oedometer tests on Yoldia clay. The approach followed consists in a first analysis where the separation of strains is applied to the consolidation curves. During this phase, primary consolidation strains are filtered from creep by using Brinch-Hansen, Taylor and ANACONDA method. The second phase of the interpretation aims to determine the preconsolidation stress according to three different theories (Akai, Janbu and Casagrande - Terzaghi). The preconsolidation stress values, as well as the consolidation curves, are slightly influenced by the separation of strains method applied, while using different preconsolidation stress theories deeply affects the final results.
\end{abstract}

\section{Introduction}

In the geotechnical engineering practice, it would be convenient to know how to treat systematically each specific kind of soil. But most of the time, the most accurate way to interpret laboratory tests is not identified and the results are affected by the experience and personal judgment of the operator. The aim of this research is to identify the most representative interpretation for consolidation tests on different Danish soils. Previous works tried to illustrate the difficulties occurring during the interpretation of oedometer tests $[1,2]$. This specific article deals with the interpretation of consolidation tests on Yoldia clay.

Oedometer test is a test investigating one-dimensional (1D) soil deformation characteristics, soil stiffness and soil stress history. Oedometer results define the time effect on soil and are used to predict the settlements of a soil deposit. In order to understand oedometer results, theories for interpreting the strains and for calculating the preconsolidation stress need to be applied. A preliminary analysis involves the separation of strains between primary consolidation and creep strain, a second one discusses the preconsolidation stress interpretation.

The different separation of strains methods taken into account are Brinch-Hansen [3], Taylor [4] and ANACONDA-creep filter theory [5]. In the second phase of the interpretation, three different methods to calculate the preconsolidation stress are applied (Akai [6], Janbu [7], Casagrande-Terzaghi method discussed by Jacobsen [8]).

The present study compares the output of the different separation of strains methods combined with the different preconsolidation stress interpretation theories. The purpose is to assess the applicability of the abovementioned interpretative methods on Yoldia clay.

\section{Method}

\subsection{Material and test program}

Results of seven different oedometer tests on Yoldia clay are presented. Four tests were run on Yoldia clay from Aalborg (Test01, Test02, Test03 and Test04). This soil was taken at a depth of about $5.5 \mathrm{~m}$ underground. The effective in situ stress was equal to about $65 \mathrm{kPa}$. Three other samples come from Nørre Lyngby (Test186, Test358 and Test380). These specimens were taken at a depth equal to $2.2 \mathrm{~m}$. The effective in situ stress was equal to about $30 \mathrm{kPa}$.

Thin strips of fine sand are commonly found in Yoldia clay. This feature affects the void ratio of the soil and so its behaviour during the test. In the samples tested, the amount of sand is found to be in between 1-4\%. The grain size varies between $0.0014 \mathrm{~mm}$ to $1.0 \mathrm{~mm}$. Moreover, the samples from Aalborg are characterised by the absence of the Yoldia mussel, so this clay type is more specifically called Aalborg Clay [9]. The soil properties got from characterization tests are listed in Table 1. Samples from Nørre Lyngby present lower $w$ and $e_{0}$, probably because of the different amount of sand.

The ILO (Incremental Load Oedometer) tests were performed by using the Aalborg University oedometer (Fig. 1). This tool was designing by Moust Jacobsen [10] and it aims to reduce inaccuracies due to the deformation of the apparatus itself. The AAU oedometer implies a hanging weight and a traditional cell, but the weight is applied through a ball connected to the top cap and the ring is a so-called floating ring.

The samples were fitted into the oedometer ring directly from the tube through a pushing tube tool. Right after, the samples were cut and levelled by hand to reach the desired height. The height and the diameter adopted for the samples from Aalborg were, respectively, $H=35$

\footnotetext{
${ }^{*}$ Corresponding author: epe@civil.aau.dk
} 
$\mathrm{mm}$ and $D=70 \mathrm{~mm}$. the samples from Nørre Lyngby were fitted into a ring with dimensions $H \times \mathrm{x} D=30 \times 60 \mathrm{~mm}$.

Table 1. Soil classification properties

\begin{tabular}{|c|c|c|c|c|c|c|}
\hline Test & $\begin{array}{c}\rho \\
\left(\mathrm{Mg} / \mathrm{m}^{3}\right)\end{array}$ & $\begin{array}{c}\rho_{d} \\
\left(\mathrm{Mg} / \mathrm{m}^{3}\right)\end{array}$ & $\begin{array}{c}w \\
(\%)\end{array}$ & $\begin{array}{c}e_{0} \\
(-)\end{array}$ & $\begin{array}{c}n \\
(\%)\end{array}$ & $\begin{array}{c}G_{s} \\
(-)\end{array}$ \\
\hline 01 & 1.84 & 1.37 & 35 & 0.97 & 0.49 & 2.69 \\
\hline 02 & 1.91 & 1.43 & 34 & 0.88 & 0.47 & 2.69 \\
\hline 03 & 1.93 & 1.45 & 34 & 0.86 & 0.46 & 2.69 \\
\hline 04 & 1.93 & 1.46 & 32 & 0.84 & 0.46 & 2.69 \\
\hline 186 & 2.01 & 1.64 & 23 & 0.61 & 0.38 & 2.66 \\
\hline 358 & 1.97 & 1.65 & 20 & 0.61 & 0.38 & 2.66 \\
\hline 380 & 2.02 & 1.74 & 16 & 0.53 & 0.35 & 2.66 \\
\hline
\end{tabular}

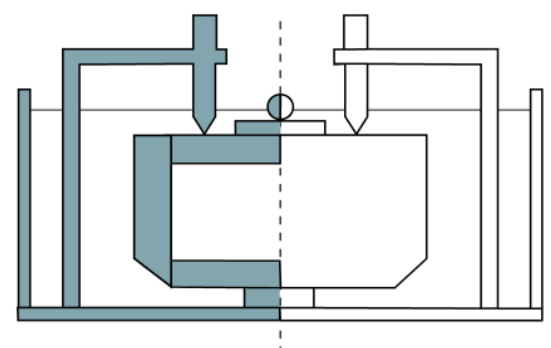

Fig. 1. AAU oedometer (not in scale).

\subsection{Separation of strains theories}

The three methods applied to separate the total strains $\varepsilon_{\text {tot }}$, between consolidation strains $\varepsilon_{\text {cons }}$, and creep strains $\varepsilon_{\text {creep, }}$, are described in this section. Different are the assumptions of these methods. Taylor assumes that the primary consolidation and creep are separate processes: the creep starts only when the primary consolidation is completed. Instead, ANACONDA states that the two consolidation phases run simultaneously.

\subsubsection{Brinch - Hansen}

Brinch-Hansen [3] develops a model where primary consolidation and creep are two separate processes. This method assumes that the consolidation strains are linear when plotted in a $\sqrt{ } t-\varepsilon$ graph, while the creep strains are linear in a $\log (t)-\varepsilon$ graph. So, the first and second part of the curve can be represented by two straight lines and their intersection represents the time when creep starts.

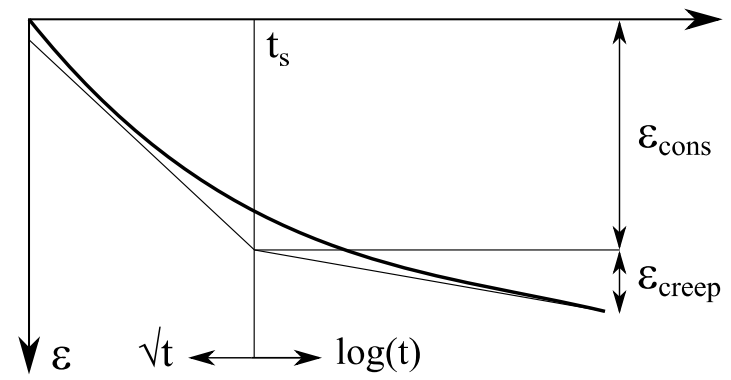

Fig. 2. Consolidation phases in a $\sqrt{t}-\log (t)$ graph.

\subsubsection{Taylor}

By using the theoretical relationship between the consolidation ratio $U$ and the square root of time factor $\sqrt{ } t$, Taylor [4] presents the square root of time fitting method. It can be observed that the $U-\sqrt{ } t$ plot is linear up to $U=60 \%$ : a straight line can fit this part of the curve. A second line, starting from the same point on the $U$ axis, is drawn with all abscissas 1.15 times higher than the first line. The intersection between this second line and the curve returns $U=90 \%$.

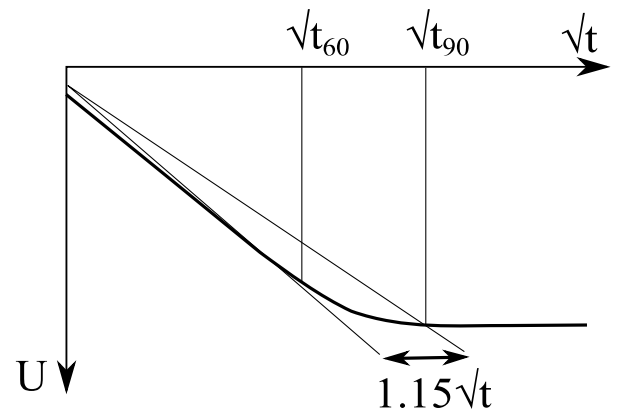

Fig. 3. Construction of the square root of time fitting method.

\subsubsection{ANACONDA}

The ANACONDA method (ANAlysis of CONsolidation test DAta) [5] considers the primary consolidation and creep being two processes running at the same time.

In Bjerrum settlement analysis [11], studying the consolidation isochrones, a strain value can be reached by primary consolidation or creep. An isochrones, at time $t=t_{A}$, quantifies the time passed in order to get a specific strain value (see Fig. 4).

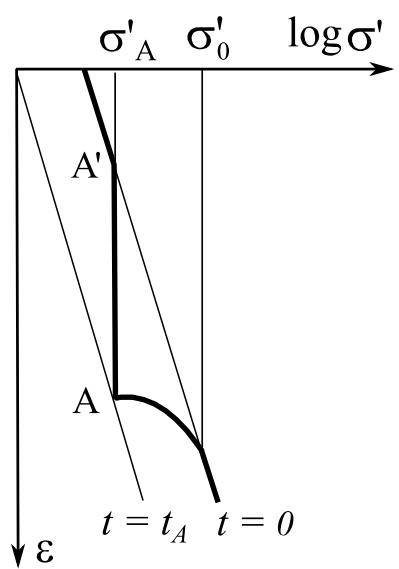

Fig. 4. Instant compression curve $t=0$ and secondary compression isochrones.

ANACONDA assumes that the primary consolidation is over at the time $t=t_{A}$ and, from that moment, the creep is the major contribute to the strains. Among the total strains $\varepsilon_{t o t}(\%)$, the difference in trend between primary consolidation strain $\varepsilon_{c}(\%)$ and creep strain $\Delta \varepsilon_{\alpha_{c}}(\%)$ is seen in the $\varepsilon-\log (t)$ graph, where the creep strains get into a straight line (see Fig. 5). 


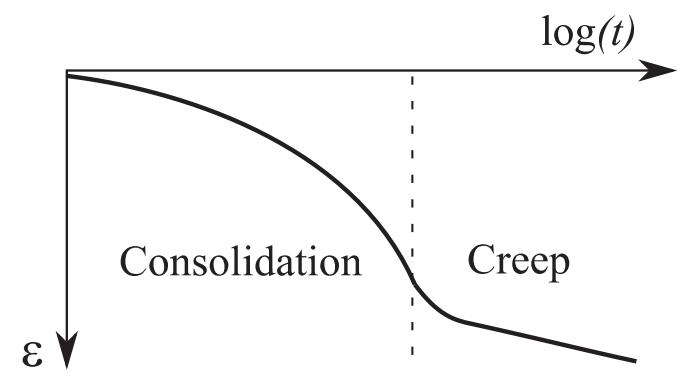

Fig. 5. Consolidation and creep.

It is possible to determine $t_{A}$ from the equation:

$$
\Delta \varepsilon_{\alpha c}=C_{\alpha \varepsilon} \log \left(1+t / t_{A}\right)
$$

where $C_{\alpha \varepsilon}$ is the secondary compression index. The wanted $t_{A}$ transforms the $\Delta \varepsilon_{\alpha_{c}}-\log \left(1+t / t_{A}\right)$ curve into a straight line, where $C_{\alpha \varepsilon}$ is the slope (see Fig. 6).

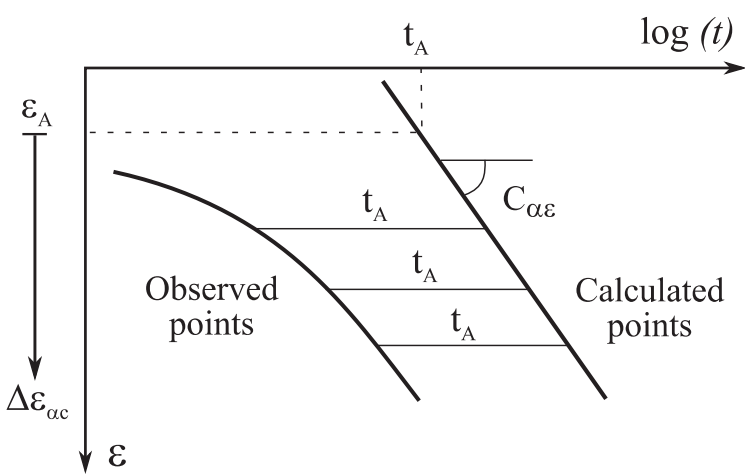

Fig. 6. Observed creep points and the auxiliary straight line.

Once the $\Delta \varepsilon_{\alpha_{c}}$ is found, in order to get the $\varepsilon_{\mathrm{c}}$ value, it is possible using the relationship:

$$
\varepsilon_{\mathrm{c}}=\varepsilon_{\mathrm{tot}}-\Delta \varepsilon_{\alpha \mathrm{c}}
$$

If after the time $t_{A}$ the slope of $\varepsilon_{c}-\log (t)$ is zero, the $\Delta \varepsilon_{\alpha_{c}}$ value is correct.

For example, Fig. 7 shows how the separation of strains is displayed in ANACONDA method. As soon as the creep becomes the major contribution, the consolidation strains line (in blue) becomes horizontal. It is the user that selects the amount of points involved in the creep strains and so determines the time $t_{A}$.

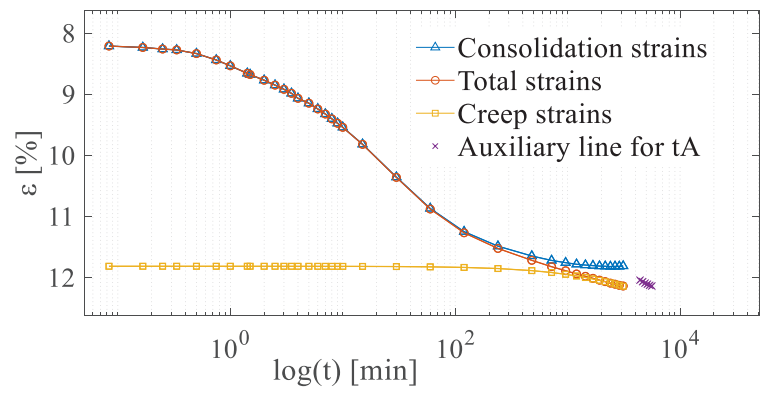

Fig. 7. Oedometer step filtered in ANACONDA.

\subsection{Preconsolidation stress theories}

The methods applied to interpret the preconsolidation effective stress $\sigma_{p c}$ ' are described in this section. The common initial assumption is the change in stiffness from a stiffer to a softer response close to $\sigma_{p c}$ '. Each of these methods relies on the knowledge of a different deformation parameter. For Akai, Janbu and CasagrandeTerzaghi, these parameters are, respectively: secondary compression index $C_{\alpha \varepsilon}$, consolidation modulus $M$ and characteristic effective stress $\sigma_{\mathrm{k}}$ '.

Janbu and Akai methods require user experience and the user subjectivity could be a source of error. Casagrande-Terzaghi, on the other hand, is based on a graphical construction and it is less time consuming than the other two methods.

\subsubsection{Akai}

The value of preconsolidation stress can be determined thanks to the knowledge of the secondary compression index $C_{\alpha \varepsilon}$. In fact, Akai [6] presents how $\varepsilon_{\alpha_{c}}$ grows linearly when the effective normal stress $\sigma^{\prime}$ is smaller than $\sigma_{p c}$ ' and, instead, it grows in a logarithmic scale $\left(\log \sigma^{\prime}\right)$ when $\sigma^{\prime}>\sigma_{p c}$ '. In this way, $\sigma_{p c}$ ' can be graphically determined as an interval where the curve $\sigma^{\prime}-\varepsilon_{\alpha_{c}}$ breaks and starts to be horizontal, as shown in Fig. 8.

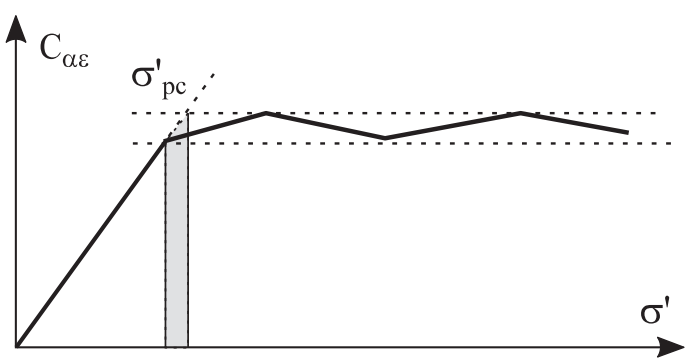

Fig. 8. Akai uses $C_{\alpha \varepsilon}$ to determine preconsolidation stress.

\subsubsection{Janbu}

The consolidation modulus $M$ is a stiffness parameter defined as:

$$
M=d \sigma^{\prime} / d \varepsilon
$$

Janbu [7] states that $\sigma_{p c}^{\prime}$ can be determined by using a $M$ - $\sigma^{\prime}$ curve, since $M$ varies with stress. In fact, where the drop of $M$ occurs and it is followed by a steady increase, it is possible to determine $\sigma_{\mathrm{pc}}$ '.

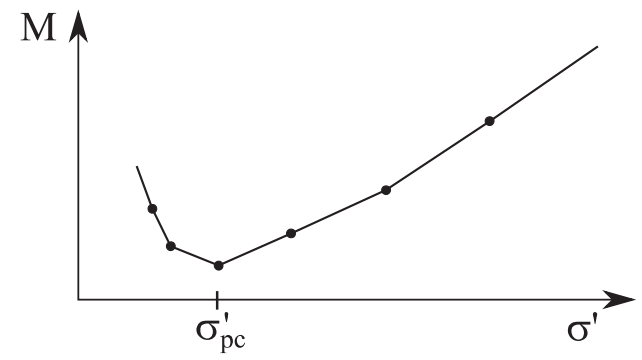

Fig. 9. Modulus $M$ and preconsolidation stress relationship. 


\subsubsection{Casagrande-Terzaghi}

Jacobsen [8] combines Terzaghi theory and Casagrande construction in order to get $\sigma_{p c}^{\prime}$ by calculating the equation:

$$
\sigma_{p c}^{\prime}=2 \cdot \sigma_{k}^{\prime}
$$

Where $\sigma_{k}^{\prime}$ (characteristic effective stress) is the stress related to the point of maximum curvature on the $\varepsilon-\log \sigma^{\prime}$ curve, as defined by Casagrande. Or, in other words, the stress value that gives to the virgin curve the starting point for the best linear approximation in the $\varepsilon-\log \sigma^{\prime}$ graph. Fig. 10 clarifies graphically these notations.

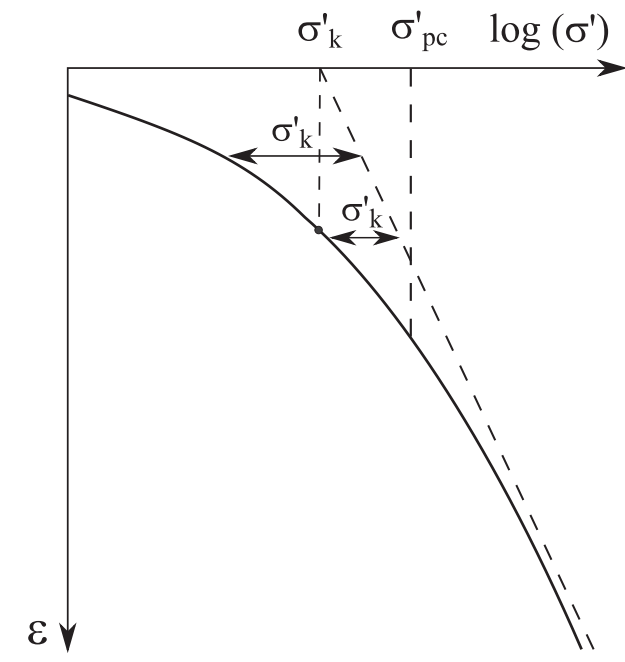

Fig. 10. Terzaghi-Casagrande construction used by Jacobsen.

\section{Results}

\subsection{Consolidation curves}

The four oedometer tests on Yoldia clay from Aalborg reached a maximum vertical stress equal to $5050 \mathrm{kPa}$. The four consolidation curves (see Fig. 11) show similar trends. The final total maximum strain varies between $\varepsilon_{\text {tot }}$ $=17 \%$ and $\varepsilon_{\text {tot }}=22 \%$.

The oedometer tests on clay from Nørre Lyngby reached a maximum vertical stress equal to $5500 \mathrm{kPa}$ and show less homogeneous trends. As it can be seen in Fig. 12 , the different tests present more variability in the virgin compression curve inclination. In this case, the final total maximum strain varies from $\varepsilon_{\text {tot }}=7.5 \%$ (Test 380$)$ to $\varepsilon_{\text {tot }}=$ $12.5 \%$ (Test186).

When the three separation of strains methods are applied to each test, the new consolidation curves are shifted upwards since the creep contribution is taken out.

As an example, the consolidation curves are plotted for Test03 in Fig. 13. At the beginning of the curve, the vertical translation is slight and it goes increasing as the load applied increases. But still, it remains negligible. Among the different methods, ANACONDA is the one closest to the unfiltered consolidation curve. Instead, Taylor presents the most remarkable difference with the unfiltered virgin compression curve, meaning that the creep contribution is higher and the consolidation strains smaller in this method.

The separation of strain is a process that relies on the user experience and the consequent subjectivity can be source of error. ANACONDA proved to be preferred to run when the load steps last enough time to provide a longer creep phase. Therefore, also the laboratory procedure influences the applicability of a method as well.

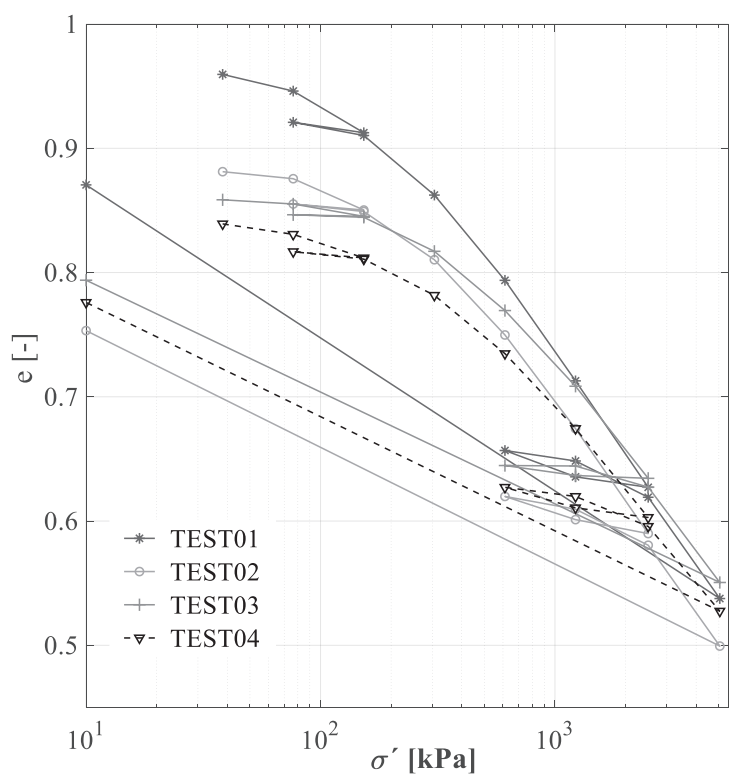

Fig. 11. Yoldia clay from Aalborg: consolidation curves where no separation of strains is applied.

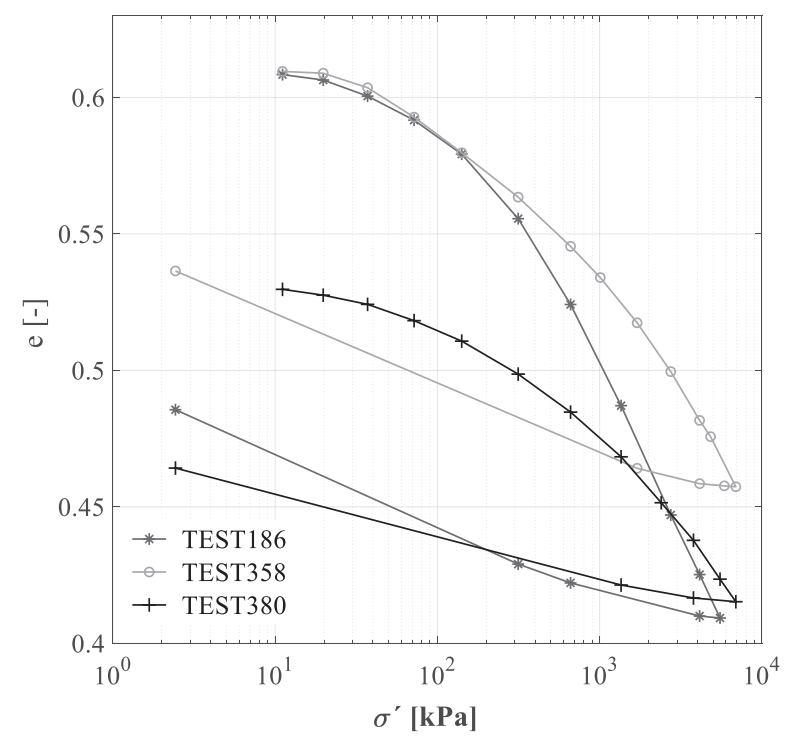

Fig. 12. Yoldia clay from Nørre Lyngby: consolidation curves where no separation of strains is applied. 


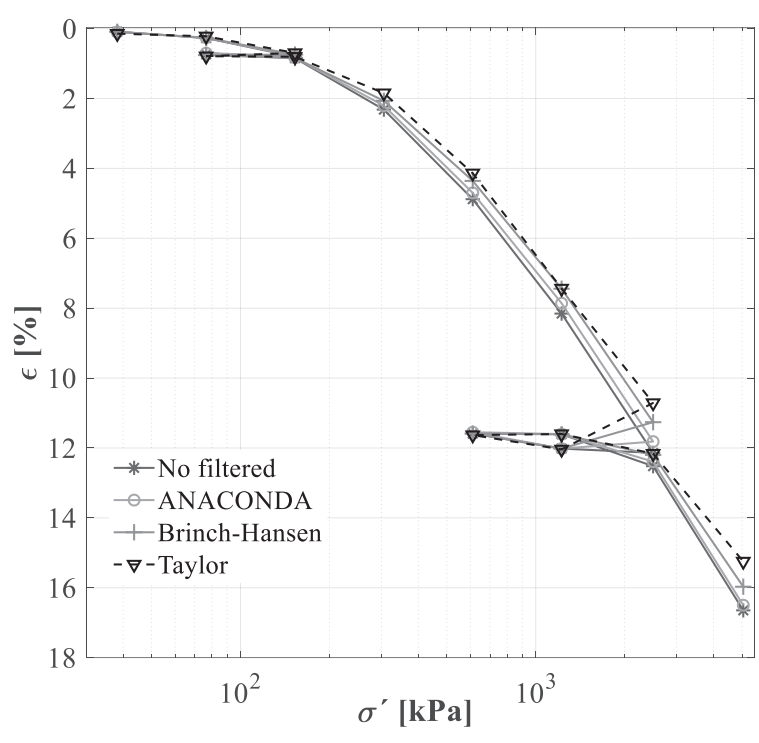

Fig. 13. Different separation of strains methods on Test 03 .

\subsection{Preconsolidation stress}

Second part of the investigation aims to define the preconsolidation stress. Akai, Janbu and Casagrande-

Table 2. Preconsolidation stress $\sigma_{p c}^{\prime}$

\begin{tabular}{|c|c|c|c|c|c|c|c|c|c|c|c|c|}
\hline $\begin{array}{c}\text { Separation of } \\
\text { strain methods }\end{array}$ & \multicolumn{3}{|c|}{ No filter } & \multicolumn{3}{c|}{ Brinch - Hansen } & \multicolumn{3}{c|}{ Taylor } & \multicolumn{3}{c|}{ ANACONDA } \\
\hline $\begin{array}{c}\text { Preconsolidation } \\
\text { stress theories }\end{array}$ & Akai & Janbu & Casa. & Akai & Janbu & Casa. & Akai & Janbu & Casa. & Akai & Janbu & Casa. \\
\hline Test & {$[\mathrm{kPa}]$} & {$[\mathrm{kPa}]$} & {$[\mathrm{kPa}]$} & {$[\mathrm{kPa}]$} & {$[\mathrm{kPa}]$} & {$[\mathrm{kPa}]$} & {$[\mathrm{kPa}]$} & {$[\mathrm{kPa}]$} & {$[\mathrm{kPa}]$} & {$[\mathrm{kPa}]$} & {$[\mathrm{kPa}]$} & {$[\mathrm{kPa}]$} \\
\hline Test01 & - & 240 & 335 & 330 & 240 & 383 & 340 & 210 & 330 & 280 & 240 & 382 \\
\hline Test02 & - & 320 & 560 & 380 & 400 & 773 & 420 & 320 & 590 & 380 & 340 & 629 \\
\hline Test03 & - & 600 & 840 & 720 & 590 & 1070 & 750 & 550 & 1100 & 590 & 306 & 967 \\
\hline Test04 & - & 380 & 578 & 500 & 405 & 755 & 550 & 350 & 733 & 500 & 362 & 648 \\
\hline Test186 & - & 150 & 295 & 280 & 150 & 570 & 300 & 220 & 530 & 200 & 200 & 310 \\
\hline Test358 & - & 200 & 735 & 250 & 200 & 645 & 280 & 200 & 615 & 200 & 180 & 620 \\
\hline Test380 & - & 180 & 654 & 265 & 190 & 713 & 300 & 220 & 1500 & 230 & 200 & 751 \\
\hline
\end{tabular}

\section{Discussion}

In the present study, the analysis of oedometer tests involves two main phases: the separation of strains between consolidation strains and creep strains, and the interpretation of preconsolidation stress.

All the separation of strains methods, as well as Akai and Janbu among the interpretation of preconsolidation stress theories, are affected by the personal judgment and experience of the user. Instead, Casagrande-Terzaghi theory, based on a graphical construction, gives less freedom to individual interpretation.

For a better performance of ANACONDA method, each single load step should be as long as possible, to make easier the separation of creep, as explained in Section 2.2.3. This means running oedometer tests with longer time steps to get the proper result.

It is common inaccurate practice to adopt a separation of strains based on the first 24 hours of testing. By using the other separation of strains methods (i.e.
Terzaghi are applied to each curve, filtered with different separation of strains methods. Table 2 shows the resulting preconsolidation stresses $\sigma_{p c}^{\prime}$.

More creep is filtered out by the strain separation method, more appreciable is the difference between no filtered consolidation curve and filtered curves. Since Akai method is based on the secondary compression index, when no separation of strains is applied, there is no result for this method.

It clearly appears how the different separation of strains methods (or considering the unfiltered consolidation curve) do not change consistently the results.

Janbu and Akai methods return preconsolidation stresses that are usually lower than the ones estimated by Casagrande-Terzaghi. Exception is made by Test03, the only one showing much more variability in the preconsolidation stresses resulting from different separation of strains methods. Interesting are also Test01 and Test186, where separation of strains and preconsolidation stress interpretation methods return the most homogeneous results.
ANACONDA), it is proved that the primary consolidation on Yoldia clay takes less than 24 hours. By adopting the 24 hours method, the user overestimates the consolidation strains and underestimates the creep contribution. In the design this would result in calculating too large settlements.

Another variable to take into account is the content of sand, commonly found in the form of slight stripes in Yoldia clay deposits.

Main considerations on the results are the following:

- At the beginning of the study, the expectation was to get a higher value of preconsolidation stress $\sigma_{p c}$ for the samples with lower initial void ratio $e_{0}$ and lower natural water content $w$ (so, for the samples from Nørre Lyngby). Instead, as shown in Fig. 14, Fig. 15 and Fig. 16 preconsolidation stresses for these samples are lower and no relationship between void ratio and preconsolidation stress is found.

- It is important that the loads applied are high enough to reach a constant inclination in the virgin compression line and so the true preconsolidation stress. 
- Generally, the use of different separation of strains methods or unfiltered strains do not influence the preconsolidation stress.

- Different methods to estimate the preconsolidation stress return widely different results. CasagrandeTerzaghi returns a preconsolidation stress considerably higher than the ones calculated by Akai and Janbu, which instead, are more consistent between each other. This difference should be subject of further investigation.

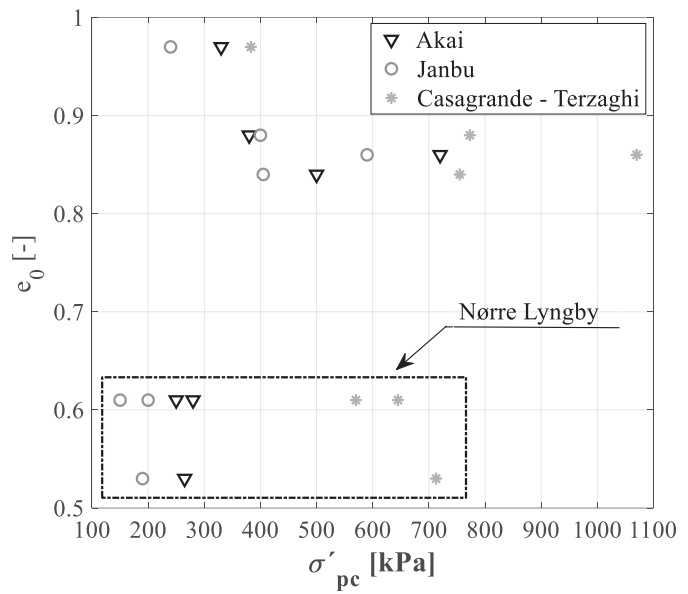

Fig. 14. Initial void ratio related to preconsolidation stresses when Brinch-Hansen is applied.

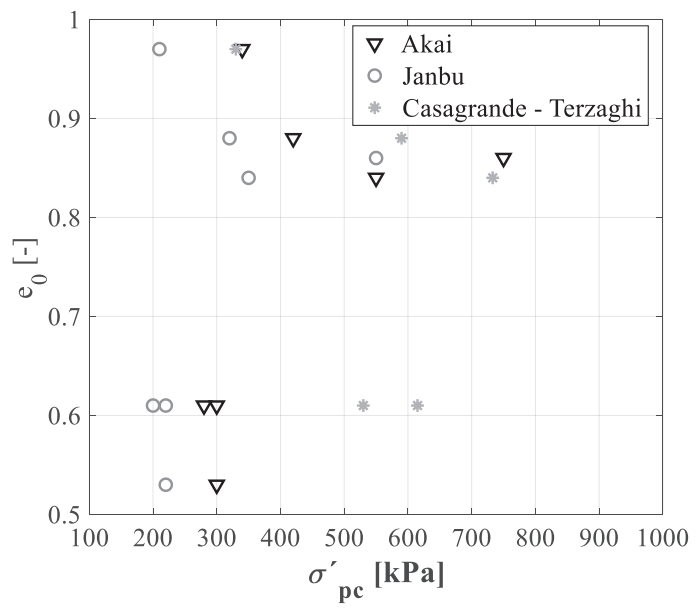

Fig. 15. Initial void ratio related to preconsolidation stresses when Taylor is applied.

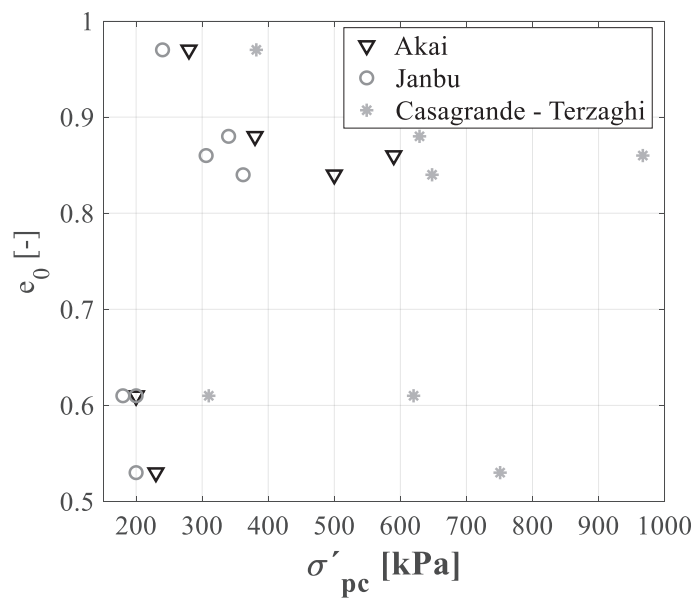

Fig. 16. Initial void ratio related to preconsolidation stresses when ANACONDA is applied.

\section{Conclusion}

A more reliable engineering design can be achieved by interpreting objectively the consolidation behaviour of a soil. Oedometer results on Yoldia clay from two different locations in Denmark are studied in this light. Different methods to separate the strains [3-5] and theories to calculate the preconsolidation stress [6-8] are applied.

Different separation of strains methods do not influence the preconsolidation stress (with exception of the 24 hours method, source of errors). Instead, the results are consistently affected by different preconsolidation stress theories.

Among the methods adopted, Casagrande - Terzaghi construction returns a higher preconsolidation stress than Akai and Janbu method. It is not possible to estimate an interval to which the preconsolidation stress belongs. Moreover, the expectation of a higher preconsolidation stress related to lower initial void ratio and water content is unfulfilled. No relationship between initial void ratio and preconsolidation stress is found.

The laboratory procedure influences the results as well. In fact, it is important to run tests with high enough loads, able to reach a constant inclination in the virgin compression line and so the true preconsolidation stress.

\section{References}

1. J. Grozic, T. Lunne, S. Pande, Can. Geotech. J. 40, 857 (2003)

2. S. J. Boone, Can. Geotech. J. 47, 281 (2010)

3. J. Brinch Hansen, A Model Law for Simultaneous Primary and Secondary Consolidation (Copenhagen Danish Geotechnical Institute, 1961)

4. D. W. Taylor, Fundamentals of Soil Mechanics (John Wiley \& Sons, 1948)

5. G. L. Grønbech, L. B. Ibsen, B. N. Nielsen, Proc. 16th Nord. Geotech. Meet. 85-94 (2012)

6. K. Akai, De Strukturellen Eigenschaften von Schluft Mitteilugen (in German) (1960)

7. N. Janbu, Proc. 7th Int. Conf. Soil Mech. 191-196 (1969)

8. M. Jacobsen, 11th Nord. Geotech. Meet. 455-460 (1992)

9. K. M. Iversen, B. N. Nielsen, A. H. Augustensen, Strength Properties of Aalborg Clay (DCE Technical Reports, No. 92, 2010)

10. M. Jacobsen, Danish Geotech. Inst. 27, 7 (1970)

11. L. Bjerrum, Géotechnique 17, 83 (1967) 